\title{
Control of oxidative stress by the Keap1-Nrf2 pathway
}

\author{
J. D. Stewart · J. G. Hengstler $\cdot$ H. M. Bolt
}

Published online: 23 March 2011

(C) Springer-Verlag 2011

Antioxidative defense mechanisms represent a cutting-edge topic of our journal (Yang et al. 2009; Cederbaum et al. 2009; Kell 2010; Dewa et al. 2009; Schumann et al. 2009; Schug et al. 2008). Many antioxidative defense proteins share common transcriptional control by the Keap1-Nrf2 pathway. The first step in transcriptional activation of these antioxidative defense factors is the reaction of inducers with cysteine residues of Keap1. The Keap1 homodimer binds the transcription factor Nrf2 and facilitates its ubiquitination and proteasomal degradation. Upon modification of cysteine residues of the sensor protein Keap1, it looses its Nrf2-binding capacity. As a consequence, Nrf2 will accumulate, translocate to the nucleus, and induce transcription of cytoprotective genes.

In the current issue of our journal, we present two review articles focussing on different aspects of the Keap1Nrf2 pathway (Baird and Dinkova-Kostova 2011; Slocum and Kensler 2011; this issue). Baird and Dinkova-Kostova from the University of Dundee focus on models of regulation of the Keap1-Nrf2 pathway. The models discussed include the "sequester and release theory", the "hinge and latch model", the model of Keap1 nucleocytoplasmic shuttling, and also Keap1-independent mechanisms of Nrf2 activation. This is followed by a comprehensive review of the cytoprotective functions of Nrf2-target gene products and an in-depth discussion of the chemistry of inducers.

Stephen L. Slocum and Thomas W. Kensler from Baltimore and Pittsburgh focus on genetic mouse models

J. D. Stewart $(\varangle)$ · J. G. Hengstler · H. M. Bolt Leibniz Institut für Arbeitsforschung an der TU Dortmund, Leibniz Research Centre for Working Environment and Human Factors (IfADo), Ardeystrasse 67, 44139 Dortmund, Germany e-mail: stewart@ifado.de of the Keap1-Nrf2 pathway and the "dark side of Nrf2", namely its role in carcinogenesis.

Together both review articles give an excellent overview of Keap1-Nrf2 as a "double edged sword" which protects healthy cells from oxidative stress, but can also be exploited by tumor cells to survive under the adverse conditions of the tumor microenvironment.

\section{References}

Baird L, Dinkova-Kostova AT (2011) The cytoprotective role of the Keap1-Nrf2 pathway. Arch Toxicol. doi 10.1007/s00204-0110674-5 (this issue)

Cederbaum AI, Lu Y, Wu D (2009) Role of oxidative stress in alcohol-induced liver injury. Arch Toxicol 83:519-548

Dewa Y, Nishimura J, Muguruma M, Jin M, Kawai M, Saegusa Y, Okamura T, Umemura T, Mitsumori K (2009) Involvement of oxidative stress in hepatocellular tumor-promoting activity of oxfendazole in rats. Arch Toxicol 83:503-511

Kell DB (2010) Towards a unifying, systems biology understanding of large-scale cellular death and destruction caused by poorly liganded iron: Parkinson's, Huntington's, Alzheimer's, prions, bactericides, chemical toxicology and others as examples. Arch Toxicol 84:825-889

Schug M, Heise T, Bauer A, Storm D, Blaszkewicz M, Bedawy E, Brulport M, Geppert B, Hermes M, Föllmann W, Rapp K, Maccoux L, Schormann W, Appel KE, Oberemm A, GundertRemy U, Hengstler JG (2008) Primary rat hepatocytes as in vitro system for gene expression studies: comparison of sandwich, Matrigel and 2D cultures. Arch Toxicol 82:923-931

Schumann A, Bauer A, Hermes M, Gilbert M, Hengstler JG, Wilhelm C (2009) A rapid and easy to handle thermoluminescence based technique for evaluation of carbon tetrachloride-induced oxidative stress on rat hepatocytes. Arch Toxicol 83:709-720

Slocum SL, Kensler TW (2011) Nrf2: control of sensitivity to carcinogens. Arch Toxicol. doi:10.1007/s00204-011-0675-4 (this issue)

Yang CS, Lambert JD, Sang S (2009) Antioxidative and anticarcinogenic activities of tea polyphenols. Arch Toxicol 83:11-21 